\title{
Fast and Slow Dynamics in DC/DC Converters with MPPT for Applications in Photovoltaic Systems
}

\author{
Yesika A. Gutiérrez \\ Grupo GIMEL, Departamento de Ingeniería \\ Eléctrica, Universidad de Antioquia Calle 70 \\ No 52-21, Medellín 050010, Colombia.
}

ORCID: 0000-0003-4265-9885

Juan B. Cano-Quintero

Grupo GIMEL, Departamento de Ingeniería, Universidad de Antioquia Calle 70 No 52-21, Medellín 050010, Colombia.

\author{
Nicolás Muñoz-Galeano \\ Grupo GIMEL, Departamento de Ingeniería, \\ Universidad de Antioquia Calle 70 \\ No 52-21, Medellín 050010, Colombia.
}

ORCID: 0000-0002-3794-0982

ORCID: 0000-0003-1407-5559

ORCID: 0000-0003-4767-1007

\author{
Jesús M. López-Lezama \\ Grupo GIMEL, Departamento de Ingenieria, Universidad de \\ Antioquia Calle 70 No 52-21, Medellín 050010, Colombia.
}

ORCID: 0000-0002-2369-6173

\begin{abstract}
This paper presents an analysis concerning to the slow and fast dynamics for DC/DC Boost converters in photovoltaic applications. Two converters with classical Proportional Integrative (PI) control and Maximum Power Point Tracker (MPPT) with the same parameters and operation conditions are implemented by means of simulation. Simulations were done in OpenModelica using specialized libraries with solar modules, power electronics components and controls blocks. Results show that simulations with irradiance data and MPPT considering fast dynamics are only viable for short time periods due to it is necessary high computer resources. In contrast, results taking into account slow dynamics allow more large simulations with minor computational cost due to there are only considered average values of fast dynamics. Therefore, slow dynamics could be considered to simulate systems as micro-grids in OpenModelica.
\end{abstract}

Keywords: Renewable energy, solar panel, Boost converter, MPPT, fast and slow dynamics, power electronics.

\section{INTRODUCTION}

Renewable sources constitute an appealing alternative for generating clean electrical energy with low emissions. Nevertheless, the fluctuating nature of renewable sources brings along challenges concerning stability, protection and connection issues with the electrical grid. Therefore, electrical energy generation with renewable sources needs a management system for ensuring optimal behavior, security and coordination of all energy sources including main grid. These systems can be configured into micro-grids which main objective is to provide electricity and integrate wind and solar energy [1]-[3].

Solar energy has grown $12 \%$ in 2019 according to data of REN21, representing a $2.8 \%$ of world electricity generation [4]. This generation source provides electrical energy without polluting emissions, low maintenance requirements and its installation can be done close to load. Photovoltaic systems are composed of solar panels and need power electronics devices such as DC/DC converters for regulating panel voltage. There are several DC/DC converter topologies for regulating DC voltage, some of them are boost, cuk and sepic converters that allow controlling the energy taken from the solar panel [5]. The most common topology in photovoltaic applications is boost converter due to its low control requirements and low power losses [6].

The main function of a DC/DC converter in a photovoltaic system is the Maximum Point Power Tracker (MPPT). The solar panel actuates as a current source while its control scheme based on MPPT modifies the panel voltage. Control with MPPT is important since the irradiance is variable and it depends on weather, time of day, as well as elements that can cause shadows; these situations require control actions to set the solar panel at its maximum power point. The most common MPPT algorithm is Perturbation and Observation $(\mathrm{P} \& \mathrm{O})$ that continuously modifies the voltage panel in order to obtain maximum power in an operation point [7]-[9].

A photovoltaic system can be analyzed by means of simulation in OpenModelica (OM). OM is an open source simulation program with specialized libraries (PVSystems, PhotoVoltaics and Photovoltaics_TGM) that focus on solar generation modeling. These libraries contain solar cells and modules, power electronics devices, control blocks, and MPPT algorithms. Additionally, every model allows modifying its source code. For these reasons, this paper presents an analysis of fast and slow dynamics of DC/DC converters focus on solar energy. A classical PI control with MPPT is implemented showing the dynamical behavior for both cases [10].

This paper is organized as follows: Section 1 presents a brief introduction regarding the importance of solar energy in micro-grids as well as the need of a control scheme with DC/DC converters and MPPT for ensuring a correct behavior of the solar panel. Section 2 presents the mathematical modeling of the boost converter in photovoltaic applications. In Section 3, simulations in OpenModelica are presented and analyzed. The main results are discussed in Section 4. Finally, the most relevant conclusions are presented in Section 5. 


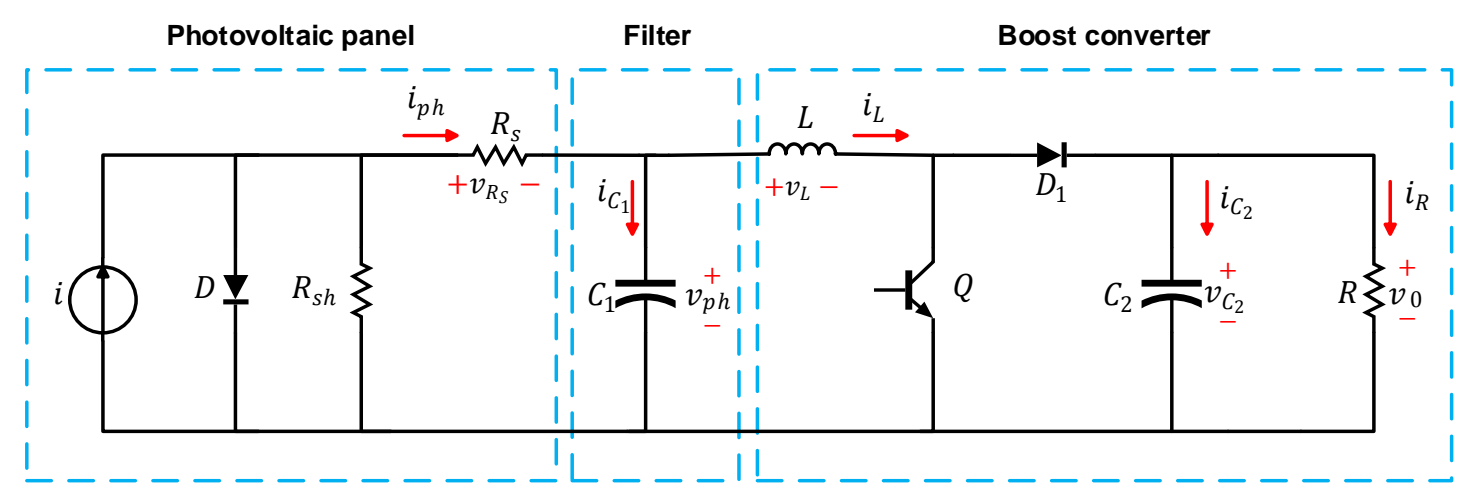

Fig. 1. Boost converter topology for photovoltaic applications.

\section{MATHEMATICAL MODELING OF THE BOOST CONVERTER}

Photovoltaic modules present low voltage levels, therefore, they require DC/DC converters to increase their output voltage. The most common topology is the boost converter, which is illustrated in Fig. 1 where the feeding source is a photovoltaic panel. The panel model has a current source $(i)$ a diode $(D)$ and two resistances $\left(R_{s}, R_{s h}\right)$. Capacitor $C_{1}$ actuates as filter between the solar panel and the boost converter. The boost converter has an inductor $(L)$, a diode $(D)$, a capacitor $\left(C_{2}\right)$, a load $(R)$ and a switch $(Q)$ for performing control actions [11].

The differential equations that describe the dynamical behavior of input current $i_{L}$, solar panel voltage $v_{p h}$ and output voltage $v_{o}$ are presented in Equations (1), (2) and (3) respectively. Variable $u$ corresponds to control action of $Q$, $u=0$ when $Q$ is open and $u=1$ when $Q$ is closed [12].

$C \frac{d i_{L}}{d t}=v_{p h}-(1-u) v_{0}$

$C_{1} \frac{d v_{p h}}{d t}=i_{p h}-i_{L}$

$C_{2} \frac{d v_{0}}{d t}=(1-u) i_{L}-\frac{v_{0}}{R}$

\section{SIMULATIONS IN OPENMODELICA}

This section presents the simulations results in OpenModelica using the specialized library PVsystems that provides elements as solar modules, electrical elements and control blocks including MPPT based on P\&O algorithm.

\section{III.I SIMULATIONS IN OPEN LOOP}

Two boost converters with the same elements were evaluated considering the same simulation conditions (see Fig 2); the boost converter elements are $C_{1}=C_{i n \_1}=C_{i n \_2}=3.3 \mu \mathrm{F}$,
$C_{2}=C_{\text {out_1 }}=C_{\text {out } \_2}=3.3 \mu \mathrm{F}, \quad L=L 1=L 2=6 \mathrm{mH}$ and $R=\operatorname{Load} 1=\operatorname{Load} 2=330 \Omega$. The first converter has a switch for fast dynamics (sw) (Fig 2a), and the second one (Fig 2b) uses a switch for slow dynamics (ccm_dcm 1 ). The solar panel was feed with constant irradiance and temperature

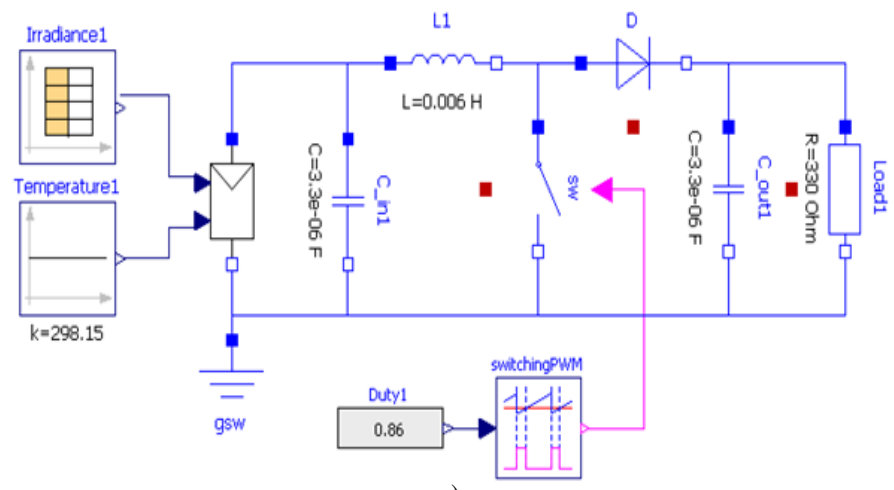

a)

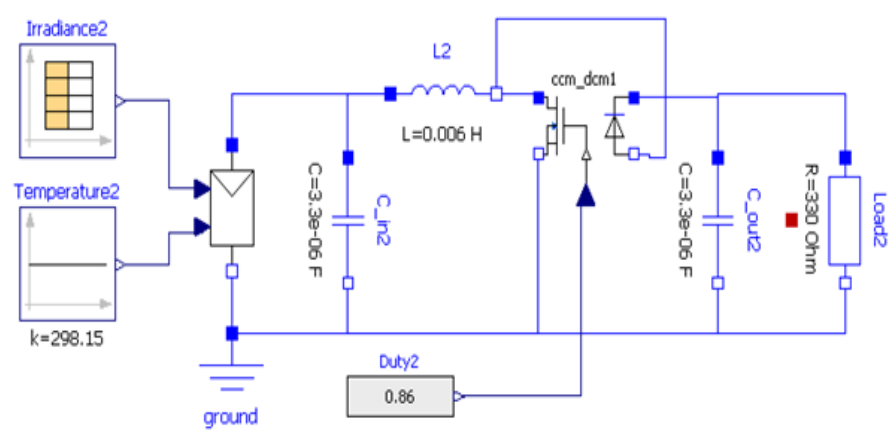

b)

Fig. 2. Boost converter schematic: a) fast dynamics and b) slow dynamics.

Fig 3 shows the output voltage response for both converters. The first converter (red curve) corresponds to the fast dynamic which presents a ripple typical of DC/DC converters due to commutation; the fast dynamic allows seeing the detail of the output voltage curve (in this case) produced by the Pulse Width Modulation (PWM). On the other hand, the blue curve corresponds to the second converter of slow dynamics. This converter presents a continuous curve without ripple only showing the average value. 
International Journal of Engineering Research and Technology. ISSN 0974-3154, Volume 13, Number 11 (2020), pp. 3255-3261

(C) International Research Publication House. https://dx.doi.org/10.37624/IJERT/13.11.2020.3255-3261

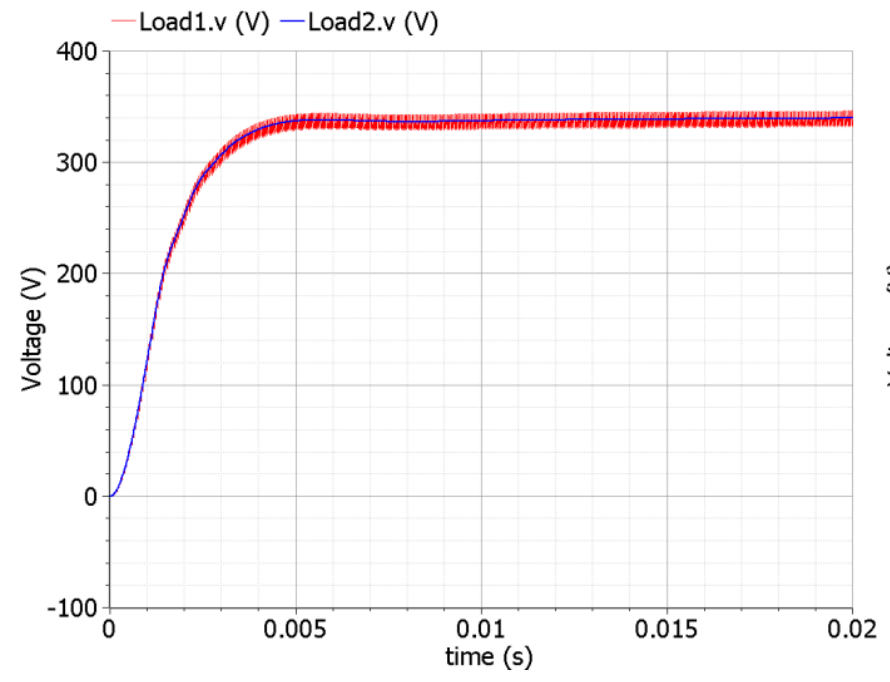

a)

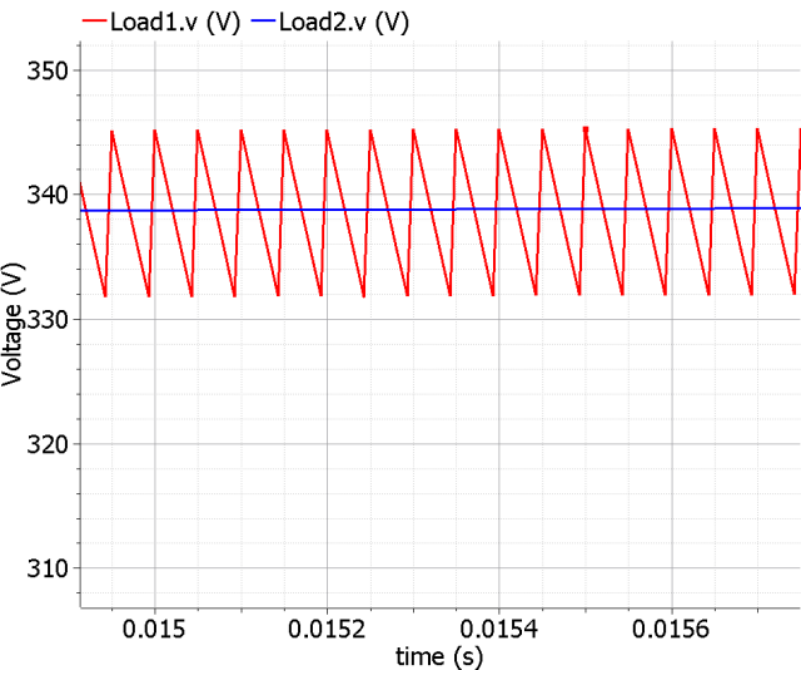

b)

Fig 3. Output voltage response: a) from start-up up to steady state and b) zoom in steady state.

\section{III.II SIMULATIONS WITH MPPT}

The MPPT block algorithm is presented in Fig 4, where Fig $4 \mathrm{a}$ shows the code provided by OpenModelica and Fig $4 \mathrm{~b}$ presents a flowchart to summarize the algorithm used to remain the panel power $\left(p_{p h}=v_{p h} i_{p h}\right)$ in its maximum value. This code corresponds to the $\mathrm{P} \& \mathrm{O}$ algorithm that increases or decreases voltage $\left( \pm \Delta v_{p h}\right)$ from solar panel for a next state if the power relation $\left[p_{p h}(t)-p_{p h}(t-1)\right]$ is greater or less than zero [13].
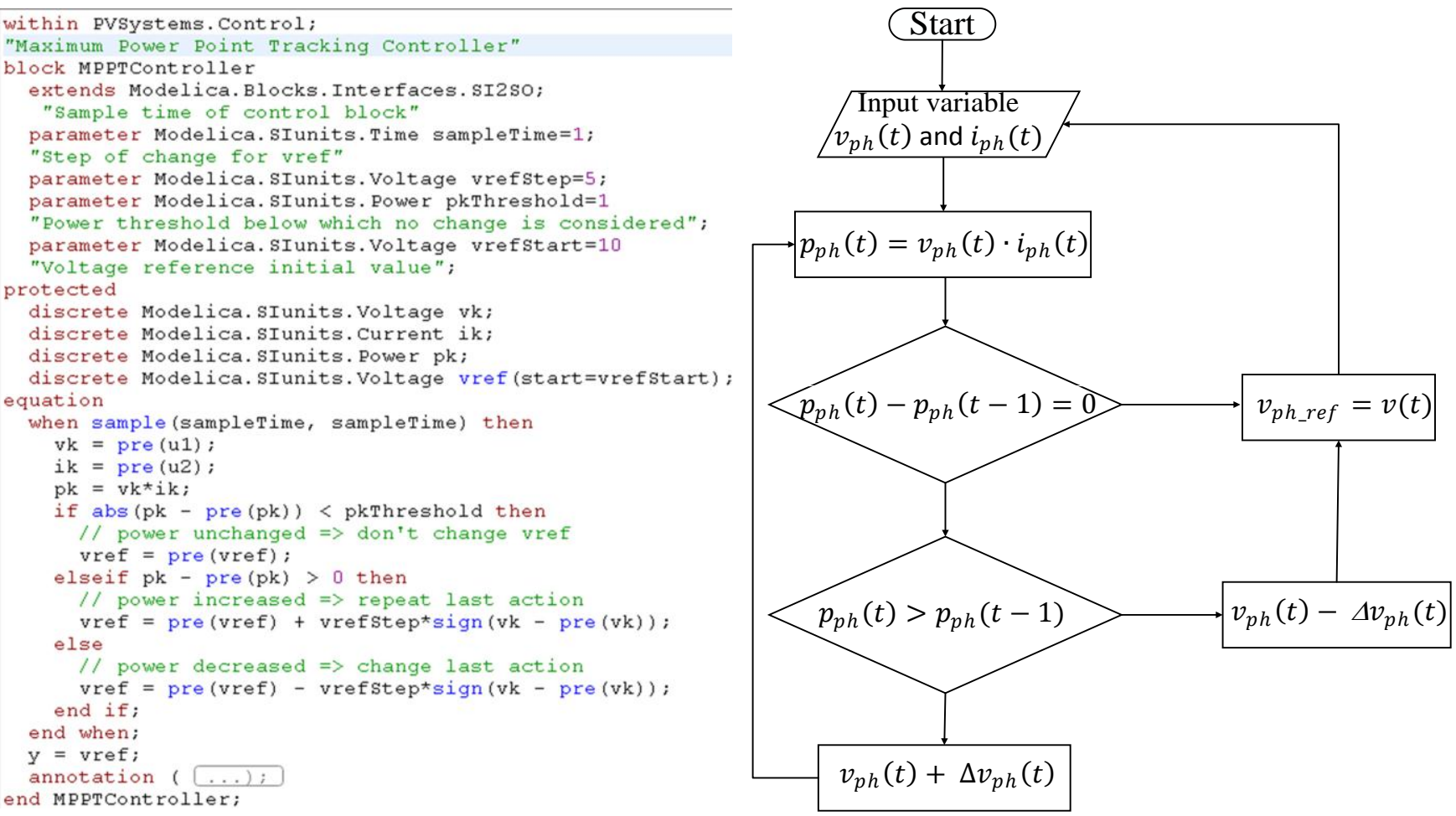

b)

Fig. 4. MPPT from OpenModelica: a) source code and b) flowchart. 
International Journal of Engineering Research and Technology. ISSN 0974-3154, Volume 13, Number 11 (2020), pp. 3255-3261

(C) International Research Publication House. https://dx.doi.org/10.37624/IJERT/13.11.2020.3255-3261

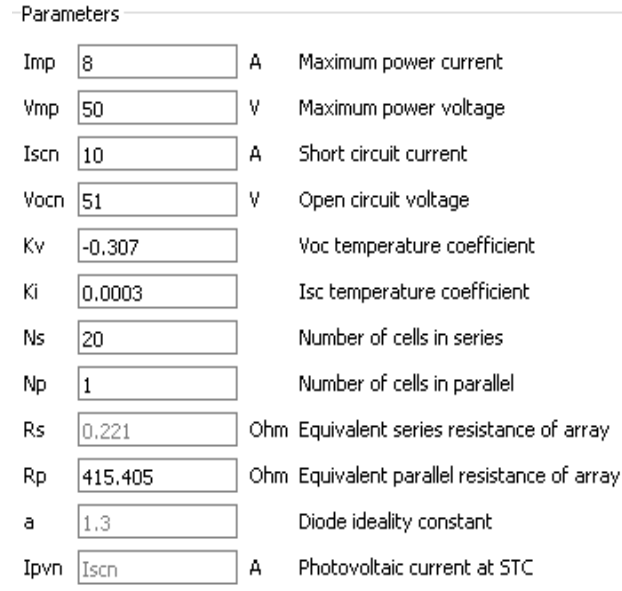

a)

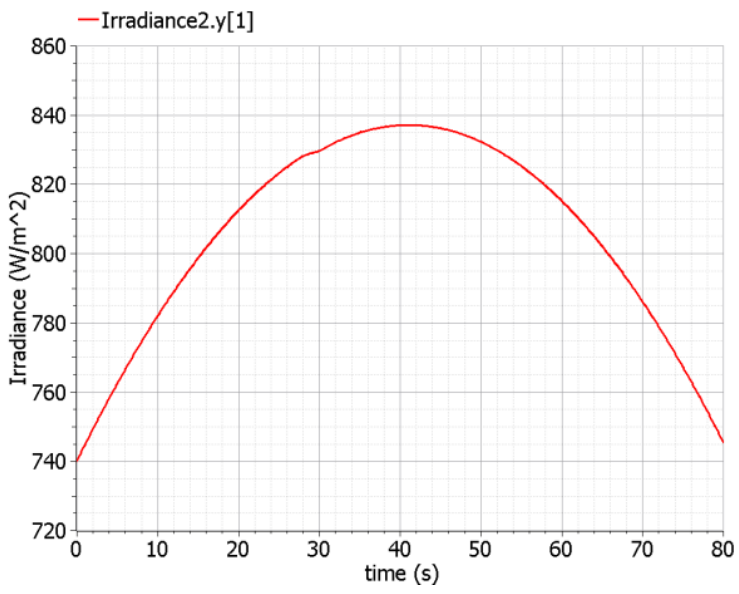

b)

Fig. 5. Solar panel configuration: a) panel data and b) irradiance curve.

Fig 5a presents solar panel data corresponding to a commercial panel with rated power $p_{p h}=400 \mathrm{w}$ and Fig $5 \mathrm{~b}$ shows the irradiance curve for the tests [14], [15].

Fig 6 presents the schematics to simulate with MPPT in close loop; Fig 6a shows the boost converter used for fast dynamics,
Fig $6 \mathrm{~b}$ shows the converter with switch for slow dynamics. The control parameters $P=2.5$ and $I=0.9$ were tuned with Laplace root locus procedure using equations (1), (2) and (3).

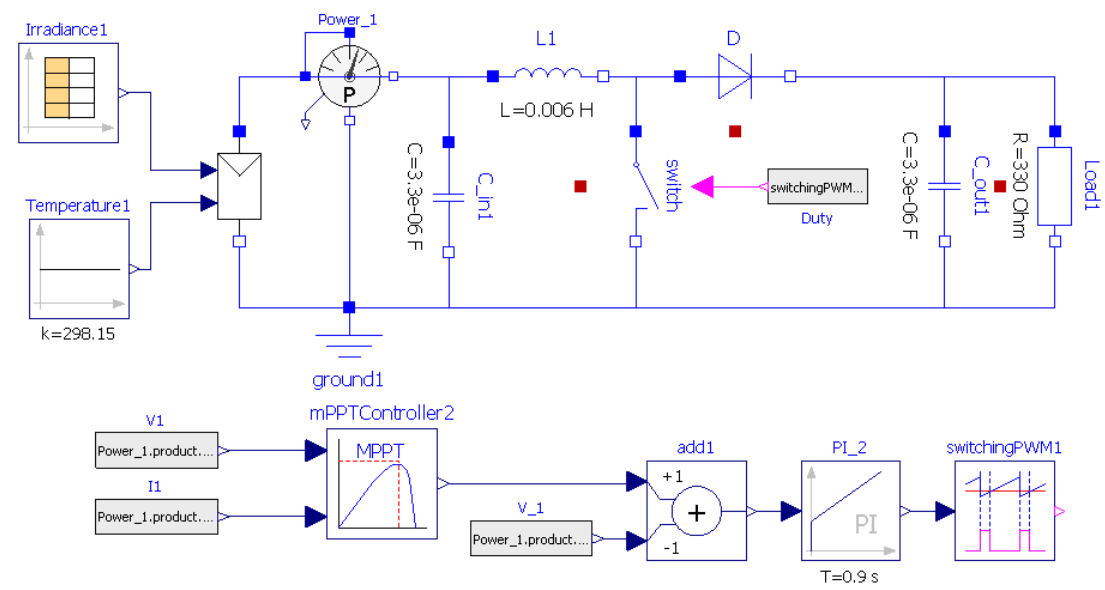

a)
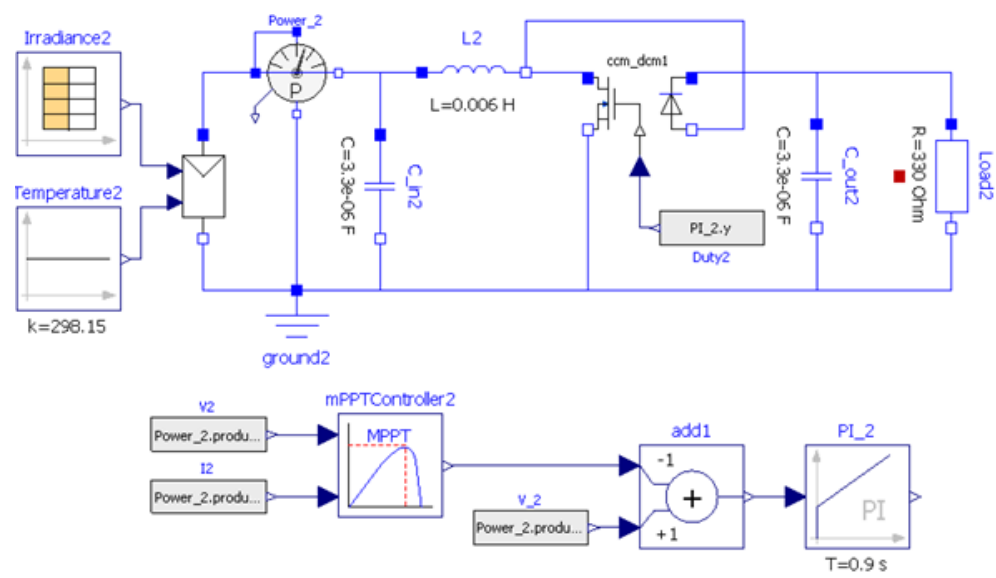

b)

Fig. 6. Boost converter with control and MPPT: a) fast dynamics and b) slow dynamics. 
International Journal of Engineering Research and Technology. ISSN 0974-3154, Volume 13, Number 11 (2020), pp. 3255-3261

(C) International Research Publication House. https://dx.doi.org/10.37624/IJERT/13.11.2020.3255-3261

Figs 7, 8 and 9 present the simulation results for output power, solar panel voltage and converter output voltage for both converters, respectively. The first converter presents the fast dynamics (Figs 7a, 8a and 9a) where it can be noted the ripple caused by MPPT block in order to find maximum power from panel according to the irradiance curve. The second converter presents the slow dynamic (Figs 7b, 8b and 9b) showing the average value for each variable; so, such a variation caused by control and MPPT only has relevance during the transitory due to the start-up.

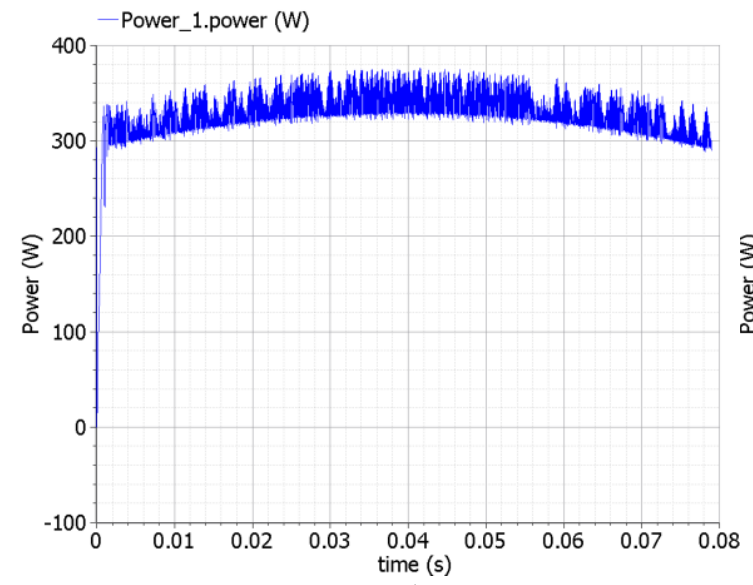

a)

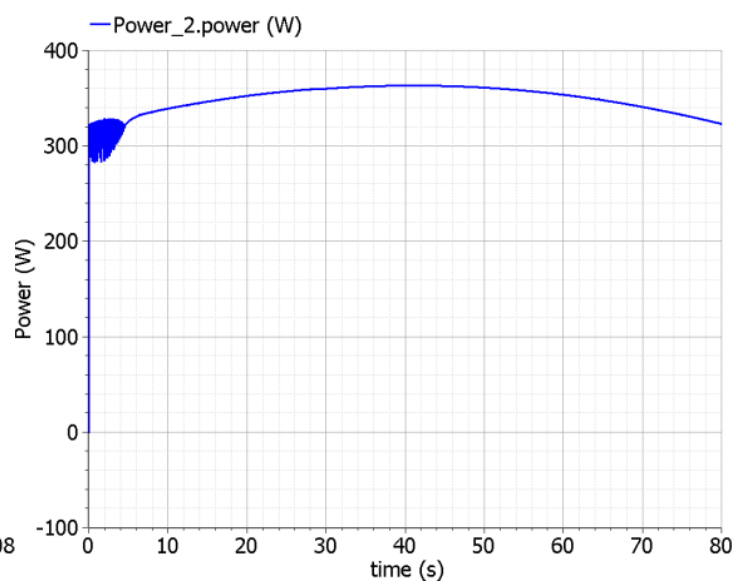

b)

Fig. 7. Output power: a) fast dynamics and b) slow dynamics.

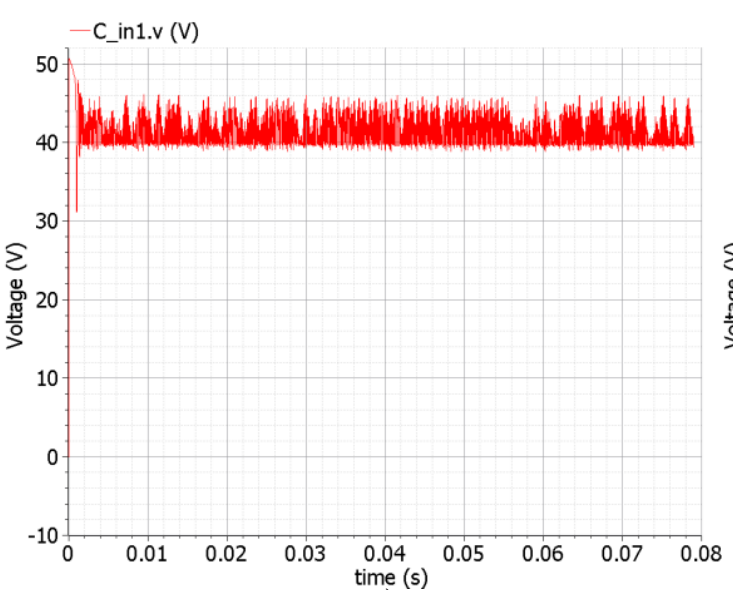

a)

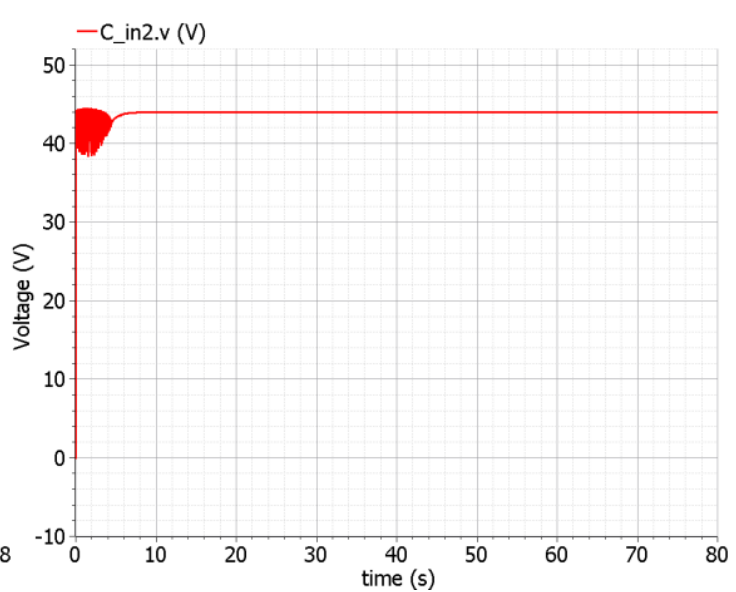

b)

Fig. 8. Solar panel voltage: a) fast dynamics and b) slow dynamics.

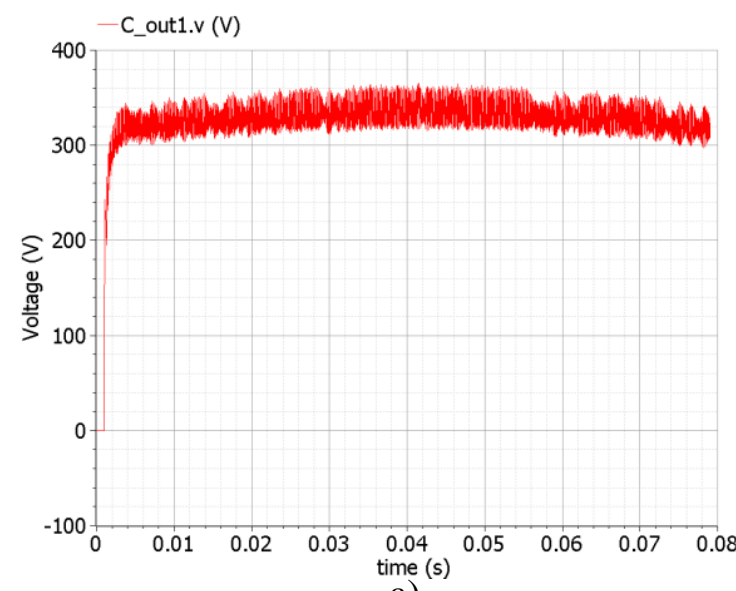

a)

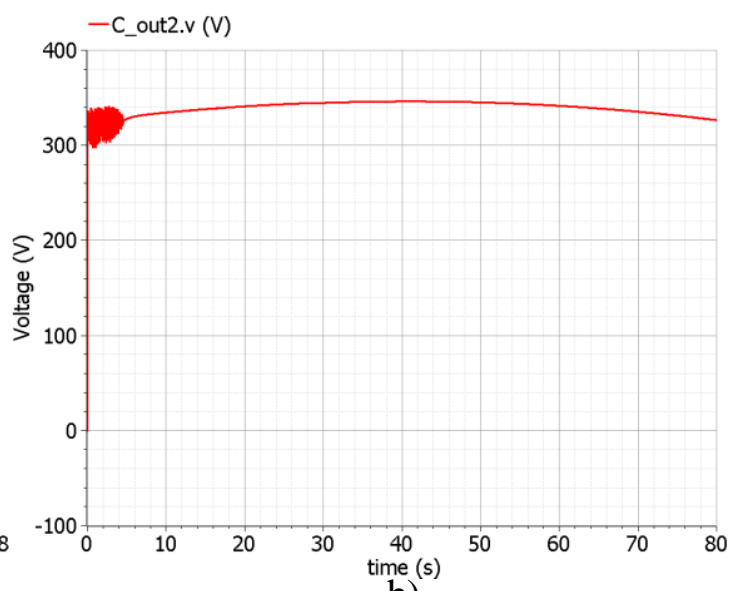

b)

Fig. 9. Boost converter output voltage: a) fast dynamics and b) slow dynamics. 


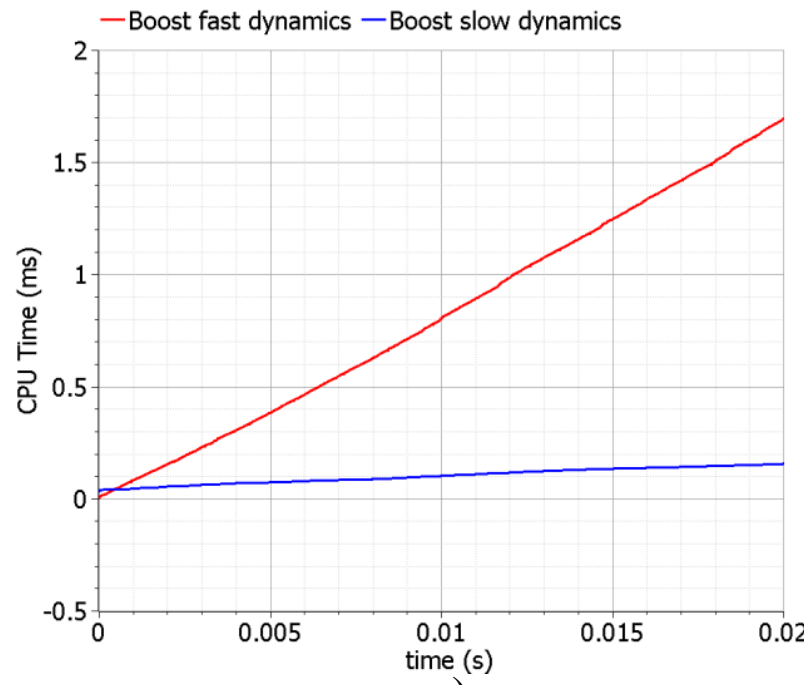

a)

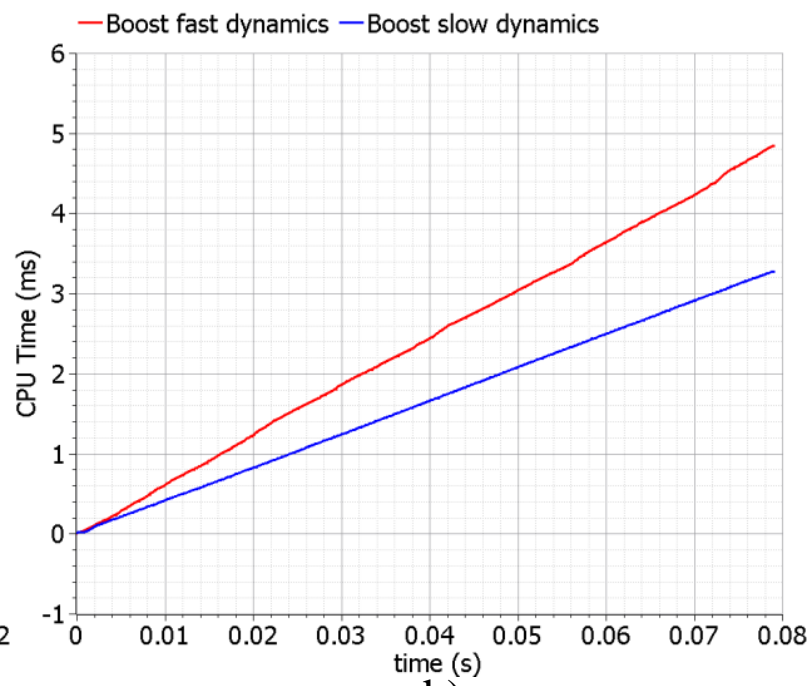

b)

Fig. 10. Total time simulation vs CPU time processing: a) open loop and b) MPPT control.

\section{DISCUSSION OF RESULTS}

The results show that the slow dynamics can be used to simulate the behavior and obtain the average value of the fast dynamics. Also, the simulation with slow dynamics requires low points to compute in comparison with fast dynamics. Fig 10 depicts the computing time for the two simulations performed in this paper. Fig 10a presents the simulation time in open loop (Figs 2 and 3) that compares the total simulation time of both converters versus CPU time processing; this result shows that the simulation considering the slow dynamics only needs approximately a $6 \%$ of CPU time compared to the time used in the fast dynamic simulation. Fig $10 \mathrm{~b}$ presents time simulations for converter with control and MPPT. In this case, CPU time for slow dynamic is approximately $60 \%$ of the time corresponding to fast dynamic.

\section{CONCLUSIONS}

In this paper, a comparison of fast and slow dynamics of DC/DC converters with applications in photovoltaic energy was presented. A boost converter topology was used due to its common implementation in solar systems. Two tests were performed with the converters in open loop and converters with control and MPPT. The implementation was done in OpenModelica simulation program in order to compare the behavior of both dynamics. Simulation results in open loop and with control considering only slow dynamics presented a better behavior (lower CPU time processing) than the simulation considering fast dynamics; the simulation only computes the average value of results when simulating the slow dynamic. Large systems such as micro-grids require high computational resources and do not need a detail simulation of each component. Therefore, modeling and simulation with slow dynamics is a better option for optimizing computational resources.

\section{Acknowledgements}

The authors gratefully acknowledge the financial support provided by the Colombia Scientific Program within the framework of the call Ecosistema Científico (Contract No. FP44842- 218-2018). Likewise, Universidad de Antioquia (Colombia) is acknowledged for the financial support through the Sostenibilidad program.

\section{REFERENCES}

[1] Kaustubh Dilip Patil, Prof. sunil . m. mahajan and Prof.Firoj.U.Pathan, «Renewable Delhi Metro», IJERT, vol. 7, pp. 161-170, Number 2014

[2] U. S. and G. D. A. Muneiah, «Micro Grid Control Methods around the World: State of Art», International Journal of Advanced Science and Technology, vol. 29, n. ${ }^{\circ} 11 \mathrm{~s}$, pp. 1326-1335, jun. 2020.

[3] R. M. Elavarasan et al., «A Comprehensive Review on Renewable Energy Development, Challenges, and Policies of Leading Indian States With an International Perspective», IEEE, vol. 8, pp. 74432-74457, 2020, doi: 10.1109/ACCESS.2020.2988011.

[4] REN21, «RENEWABLES 2020 GLOBAL STATUS REPORT». https://www.ren21.net/gsr-2020 (accedido sep. 30, 2020).

[5] R. F. Coelho, F. M. Concer and D. C. Martins, «A simplified analysis of DC-DC converters applied as maximum power point tracker in photovoltaic systems», $n$. $^{\circ}$ The 2nd International Symposium on Power Electronics for Distributed Generation Systems, pp. 29-34, Hefei 2010, doi: 10.1109/PEDG.2010.5545753.

[6] J. Vargas et al., «Análisis del uso de micro convertidores DC/DC enfocados en la extracción máxima de energía en una granja fotovoltaica», SciELO, vol. 10, pp. 205-217, mar. 2019, doi: 10.29019/enfoqueute.v10n1.441. 
[7] «Maximum Power Point Tracking With Ripple Current Orientation for Photovoltaic Applications», in IEEE Journal of Emerging and Selected Topics in Power Electronics, vol. 2, pp. 842-848, dic. 2014, doi: 10.1109/JESTPE.2014.2328577.

[8] S. Murdoch and S. Reynoso, «Design and Implementation of a MPPT circuit for a Solar UAV», IEEE, vol. 11, n. $^{\circ}$ in IEEE Latin America Transactions, pp. 108-111, feb. 2013, doi: 10.1109/TLA.2013.6502787.

[9] M. Mantilla, G. Quinones, C. Castellanos, J. Petit, y G. Ordonez, «Analysis of maximum power point tracking algorithms in DC-DC boost converters for grid-tied photovoltaic systems», en IECON 2014 - 40th Annual Conference of the IEEE Industrial Electronics Society, Dallas, TX, USA, oct. 2014, pp. 1971-1976, doi: 10.1109/IECON.2014.7048772.

[10] J. Brkic, M. Ceran, M. Elmoghazy, R. Kavlak, A. Haumer, y C. Kral, «Open Source PhotoVoltaics Library for Systemic Investigations», feb. 2019, pp. 41-50, doi: 10.3384/ecp1915741.

[11] J. Lopez-Lezama, J. Cano, y N. Munoz, «Methodology for teaching the operation principle of the boost converter: a rigorous description and solution using OpenModelica», Espacios, vol. 41, p. 25, abr. 2020.

[12] Rouzbehi, K., Miranian, A., Escaño, JM., Rakhshani, E., Shariati, N., Pouresmaeil, «A Data-Driven Based Voltage Control Strategy for DC-DC Converters: Application to DC Microgrid», 2019.

[13] Y. Ji, D. Jung, J. Kim, J. Kim, T. Lee and C. Won, «A Real Maximum Power Point Tracking Method for Mismatching Compensation in PV Array Under Partially Shaded Conditions», in IEEE Transactions on Power Electronics, vol. 26, pp. 1001-1009, abr. 2011, doi: 10.1109/TPEL.2010.2089537.

[14] Rameen S. AbdelHady, «Detecting the Parameters of Solar Cells Using Efficient Curve Fitting Techniques».

[15] Basharat Jamil and Mohd. Maroof Khan, «Estimation of Clear-Sky Solar Radiation Using ASHRAE Model for Aligarh, India», IJERT, vol. 7, pp. 227-236, Number 2014. 